\title{
End-of-Life Directives: Follow-Up Comments
}

\author{
Samuel J. Stratton, MD, MPH
}

The Editorial published in the October 2016 [31(5)] issue of Prehospital and Disaster Medicine titled "Don't Save My Life: Do-Not-Resuscitate and End-of-Life Directives in the Context of EMS and Disaster Medicine" resulted in more than the usual number of emails and Letters to the Editor. Often with Editorials, emails are received that agree with the context of the Editorial and are supportive of what has been written. This was not the case for the October 2016 Editorial. Many who read the Editorial disagreed with the points that were presented or were concerned about the implication of acceptance of end-of-life directives. The following are letters received which were selected to show two of the many perspectives regarding the original Editorial:

\section{Dear Editor:}

I am disappointed in the shallowness of your Editorial on DNR and end-of-life decisions. You address a vital, personal issue from an unfeeling, clinical viewpoint. Certainly, an emergency medical technician, nurse, or physician should understand the legal aspects of end-of-life wishes as you discuss in your Editorial, but the legal and civil rights approach you presented in the Editorial is superficial and fails to present an understanding of the deeper meaning of such a final decision a person may make.

I am a dying physician. I hurt in ways that I could never imagine. My entire current life is dealing with the pain of terminal cancer. I've had many joys in life and a very fulfilling medical career. I am content with my accomplishments and not ashamed of my failures. I've suffered the deepest sadness with the unexpected loss of one of my children and the ongoing joy of a wife who is devoted to our relationship. I've lived life as it can be experienced: happy, sad, fulfilled, and disappointed. But now, I live an existence of pain, anguish, and humiliation.

I once was a muscular, robust man who could protect my wife and children; now I'm wasted flesh and frail bones that can bleed and fracture with the simplest touch or movement. In joy, I danced with my daughter at her wedding; now my daughter silently weeps as she places me on a bedpan. As I continually vomit from the effects of chemotherapy, I'm aware that I constantly reek of the smell of puke. I am a pathetic shell of the self-confident man I was just recently. All I have left is a small piece of dignity. I know I will soon lose that bit of dignity when finally the ambulance is called and I am assaulted with needles, drugs, endotracheal tubes, and electricity in a futile effort to prolong my pain. I will lose what fragment of dignity that I have as I lay naked on an emergency room gurney with my wasted body exposed down to my genitals while flailing "heroic" medical efforts are made to "resuscitate" me.

I'm 51 years-old and will soon be dead no matter what humans do. At this point, the only control and self-worth I have left is the decision to end my life. None of the legal support for my ending my life, the social debate, or your

academic, clinical Editorial are truly relevant. None of your legal discussion or alerting EMS personnel to politicians' actions begins to address the true reality.

My end-of-life decision has been made and is soon in coming; it will simply be the end of pain and anguish with preservation of what small degree of dignity I have left. Author's name withheld by request.

\section{Dear Editor:}

We have read the Editorial entitled "Don't Save My Life: Do-Not-Resuscitate and End-of-Life Directives in the Context of EMS and Disaster Medicine" by Samuel J. Stratton published in Prehospital and Disaster Medicine, Volume 31, October 2016, pp. 463-464. We want to congratulate the author for this, and have some suggestions. Title: Islamic Perspective about Euthanasia and PhysicianAssisted Suicide

Mohammad Parvaresh-Masoud; ${ }^{1}$ Alireza Alinouri; ${ }^{2}$ Hamid Asayesh ${ }^{1}$

1. Faculty of Paramedical Sciences, Qom University of Medical Sciences, Qom, Iran

2. Assistant Professor of Theology, Qom University of Medical Sciences, Qom, Iran

\section{Correspondence:}

Hamid Asayesh

Faculty of Paramedical Sciences

Qom University of Medical Sciences

Qom, Iran

E-mail: hasayesh@gmail.com

It is necessary to seek the religious and philosophical views regarding physician-assisted suicide (euthanasia), and we would like to emphasize the Islamic approach which is about these issues. One of the main beliefs in Islam is that God (ALLAH) is the creator of all mankind and the real owner of all lives. ${ }^{1}$ According to Islamic law, medical staff should not take an active part in terminating the life of a patient, even if it is at his or her guardian's request, and even if the reason is severe deformity; a hopeless, incurable disease; or severe, unbearable pain that cannot be reduced by the usual pain killers. There are many verses in the holy Quran which are reflecting the sanctity of human life (Chapter 4, verse 29; Chapter 5, verse 32; Chapter 6, verse 151). The life is a gift from God and therefore sacred. Islamic codes reveal as God is the giver of life; he can only take the life away.

According to Muslim scholars, belief about the euthanasia in Islam is that it is unacceptable and considered as a great sin. Prophet Mohammad (PBUH) said: "None of you should wish for death because of a calamity befalling him; but if he has to wish for death, he should say: 'O Allah! Keep me alive as long as life is better for me, and let me die if death is better for me."' ${ }^{1}$ Ayatollah Khamenei, who is the 
leader of Islamic Republic of Iran, as a Shiite Muslim scholar, has issued a judgement that is considering euthanasia "in all forms" forbidden (haram), along with other well-known and respected Shiite scholars (including: Ayatollah Safi Golpaigani, NooriHamedani, MakaremShirazi, FazelLankarani, and Bahjat); all have considered all types of euthanasia, including fatal drug injection and physician-assisted suicide, as haram (forbidden) and a type of murder. ${ }^{2}$

Although, seeking medical treatments for an ill person is mandatory in Islam, illness and diseases in fact are viewed as tests for both patients and their families. Illness and pain specifically are not only a warning for the body that something is not right, but also a lesson in endurance for people that is to be thankful in times of health and patient in times of sickness. Islam does not look at the disease as just some physical ailments, but as tools for reaching the spiritual values. In this regard, both sickness and health can be tools for the faithful to get closer to the God. ${ }^{2}$

Euthanasia is an irremediable act; accordingly, it is necessary for the medical providers to attend to the probability of depression and other psychological stressors before they do anything about the requests of the incurable patients to end their lives. ${ }^{2}$ Finally, saving of a life is considered as one of the highest values and necessity in Islam. Therefore, health care providers must do everything possible to prevent premature death. ${ }^{3}$
References

1. Abu-El-Noor NI, Abu-El-Noor MK. End of life decisions: an Islamic perspective. Online Journal of Health Ethics. 2014;10(1).

2. Nikookar HR, Sooteh SHJ. Euthanasia: an Islamic ethical perspective. European Scientific Journal. 2014;2(Special Edition):179-185.
3. Hedayat KM, Pirzadeh R. Issues in Islamic biomedical ethics: a primer for the pediatrician. Pediatrics. 2001;108(4):965-971.

\section{Editor's Reply:}

As the above two letters make obvious, the issue of end-of-life directives is more important than the dry, clinical, and legal dissertation put forth in the original Editorial. End-of-life concerns require great understanding of religious, cultural, and personal ethics. My aloof and detached approach to the subject of end-of-life concerns as expressed in the October 2016 Editorial was below the publishing standards of Prehospital and Disaster Medicine. Please accept my apology.

doi:10.1017/S1049023X17000243 